\section{The Deaf Mentoring Survey: A Community Cultural Wealth Framework for Measuring Mentoring Effectiveness with Underrepresented Students}

\author{
Derek C. Braun, ${ }^{\text {t* }}$ Cara Gormally, ${ }^{\dagger}$ and M. Diane Clark ${ }^{\ddagger}$ \\ 'Department of Science, Technology, and Mathematics, Gallaudet University, Washington, \\ DC 20002; ' Deaf Studies and Deaf Education, Lamar University, Beaumont, TX 77710
}

\begin{abstract}
Disabled individuals, women, and individuals from cultural/ethnic minorities continue to be underrepresented in science, technology, engineering, and mathematics (STEM). Research has shown that mentoring improves retention for underrepresented individuals. However, existing mentoring surveys were developed to assess the majority population, not underrepresented individuals. We describe the development of a next-generation mentoring survey built upon capital theory and critical race theory. It emphasizes community cultural wealth, thought to be instrumental to the success of individuals from minority communities. Our survey targets relationships between deaf mentees and their research mentors and includes Deaf community cultural wealth. From our results, we identified four segregating factors: Being a Scientist, which incorporated the traditional capitals; Deaf Community Capital; Asking for Accommodations; and Communication Access. Being a Scientist scores did not vary among the mentor and mentee variables that we tested. However, Deaf Community Capital, Asking for Accommodations, and Communication Access were highest when a deaf mentee was paired with a mentor who was either deaf or familiar with the Deaf community, indicating that cultural competency training should improve these aspects of mentoring for deaf mentees. This theoretical framework and survey will be useful for assessing mentoring relationships with deaf students and could be adapted for other underrepresented groups.
\end{abstract}

\section{INTRODUCTION}

Science, technology, engineering, and mathematics (STEM) fields have long struggled with the underrepresentation of women, individuals from cultural and ethnic minority groups, and disabled individuals. Attrition of underrepresented individuals from STEM fields is disproportionately high (National Science Foundation [NSF], 2009). Research suggests that students who leave STEM have no discernible differences in intelligence and academic achievement from those who persist (Seymour and Hewitt, 1997; President's Council of Advisors on Science and Technology, 2012). Therefore, attrition is not related to either initial motivation or ability. Instead, feeling connected to a STEM community seems to be the most important factor for persistence (President's Council of Advisors on Science and Technology, 2012).

One way to provide that feeling of connection and STEM identity is through mentored undergraduate research experiences (Astin, 1977; Gasiewski et al., 2012; Eby and Dolan, 2015; Aikens et al., 2016). Research shows that mentored research experiences improve persistence in STEM, especially for students from underrepresented groups (Nagda et al., 1998; Barlow and Villarejo, 2004; Lopatto, 2004). These benefits accrue with longer or additional mentored research (Thiry et al., 2012). Specifically, students with mentored research experiences have increased rates of college completion, entry
Erin L. Dolan, Monitoring Editor

Submitted July 22, 2015; Revised September 26, 2016; Accepted September 27, 2016

CBE Life Sci Educ March 1, 2017 16:ar10 DOI:10.1187/cbe.15-07-0155

*Address correspondence to: Derek C. Braun (derek.braun@gallaudet.edu).

๑) 2017 D. C. Braun et al. CBE-Life Sciences Education @ 2017 The American Society for Cell Biology. This article is distributed by The American Society for Cell Biology under license from the author(s). It is available to the public under an Attribution-Noncommercial-Share Alike 3.0 Unported Creative Commons License (http://creativecommons.org/licenses/ by-nc-sa/3.0)

"ASCB $®$ " and "The American Society for Cell Biology $\circledR^{\prime \prime}$ are registered trademarks of The American Society for Cell Biology. 
into graduate-level training, and enrollment into doctoral or professional programs (Nagda et al., 1998; Hathaway et al., 2002). These students also show gains in independence, intrinsic motivation to learn, and active participation in their courses (Lopatto, 2007; Junge et al., 2010). Mentored research experiences are even remarkably effective at recruiting students into research careers who had thought they were uninterested (Villarejo et al., 2008). Perhaps most importantly, mentoring reduces the chilly climate problem often cited by students who leave STEM (McGee and Keller, 2007). This is a particular problem for students from underrepresented groups, including deaf students, who often feel unwelcome (Anscombe, 2007; Woodcock et al., 2007; Wilson et al., 2011; Hauser, 2013).

What exactly constitutes mentoring? Mentoring has been extensively defined and deconstructed, creating overlapping and sometimes conflicting paradigms (Jacobi, 1991; Saur and Rasmussen, 2003; Dawson, 2014; Eby and Dolan, 2015). Many authors rely on Jacobi's (1991) meta-analysis of the five components common to most mentoring paradigms. First, mentoring relationships focus on the mentee's achievement. Second, mentoring includes any or all of these three components: emotional and psychological support, direct assistance with career and professional development, and role modeling. Third, the relationship has reciprocal benefits for the mentee and mentor. Fourth, this relationship between the mentee and mentor is personal. Fifth, mentors have greater professional experience, influence, and success than their mentees (Jacobi, 1991, p. 513). We refer readers to Eby and Dolan (2015) for an in-depth review of research on mentoring strategies in higher education.

If mentoring is important, then common sense dictates that we should see increased student success when academic programs emphasize mentored research experiences. To do this well, programs should collect informative feedback about mentoring effectiveness. Current mentoring surveys, such as the work of Schlosser and Gelso (2001, 2005), Berk et al. (2005), and Fleming et al. (2013), were developed for students from groups well-represented in STEM and are probably adequate for assessing mentoring effectiveness with these students. However, they were not designed to capture the reasons for unsuccessful mentoring of mentees from underrepresented groups. For example, deaf scientists report that they had problems with their mentoring relationships in graduate school, citing linguistic and cultural barriers and misconceptions about deaf individuals (Anscombe, 2007; Woodcock et al., 2007). In contrast, qualitative research about mentoring with deaf individuals has shown that mentoring is highly effective when deaf mentees are paired with mentors who are also deaf (Hulsebosch and Myers, 2002; Hauser, 2013; Listman, 2013). The reasons for failures or successes of mentored research programs with students from different underrepresented groups need to be identified and routinely assessed. A survey instrument that could provide relevant feedback to the program about the mentoring relationship may help solve this problem.

One strategy to better capture the successes and failures of a mentoring relationship is to include cultural capital (Bourdieu, 1986; Thompson et al., 2015; Aikens et al., 2016). Thompson et al.'s (2015) framework used three forms of capital: human capital, or "what" you know; social capital, or "who" you know; and cultural capital, or "how" you know. However, this framework is, again, limited to an analysis of the majority group, because cultural capital traditionally reflects the cultural mores of the majority; for STEM, these are the white, nondisabled, middle-class cultural mores (Treisman, 1992; Yosso, 2005). Individuals from underrepresented groups are expected to adopt these predominant mores and behaviors. Students from other cultures who are unable to or choose not to adopt these mores and behaviors are traditionally seen as culturally poor (Irvine, 1991; Treisman, 1992; Kellam et al., 2012). Therefore, assessing mentoring relationships using a traditional view of cultural capital is insufficient, because it would further the belief that students from underrepresented groups and cultures are deficient in their cultural skills and aptitudes (Treisman, 2013).

Critical race theory contrasts the traditional view of cultural capital to offer a solution to this problem. Critical race theory identifies community as a vital part of a support network for members of underrepresented populations. The development of critical race theory scholarship began in the early 1990s and focused on giving voice to underrepresented groups (Ladson-Billings, 1998). Critical race theory posits that reality is situational and a social construct. Moreover, one's reality differs depending on one's cultural background, race, and socioeconomic status. This scholarship maintains that underrepresented populations have their own cultural capital, called community cultural wealth. Critical race theory investigates alternative epistemologies that have allowed members to survive, if not thrive, in the dominant culture.

Like some other underrepresented groups, deaf, hearing-impaired, and hard-of-hearing (henceforth, deaf) students are somewhat proportionately represented at the time of declaring an undergraduate major in STEM, that is, they are $0.8 \%$ of the student body. However, this representation drops to $0.13-0.18 \%$ of earned doctoral degrees. This means that roughly five of six deaf individuals who started an undergraduate STEM major have dropped out before completing their doctorates. Ultimately, only 33-50 deaf individuals receive doctorates annually in STEM (NSF, 2007, 2009, 2011). After two decades of legislation, including the Americans with Disabilities Act of 1990, which mandates access to traditional academic resources, an influx of deaf individuals into STEM fields should have happened by now but has not (McKee et al., 2013). In fact, the proportion of new doctorates who are deaf has actually declined over the past decade (NSF, 2007, 2009, 2011).

We need a way to assess mentoring effectiveness for students from underrepresented groups and capture variables important to these groups. Just as importantly, we need tools to provide helpful feedback to mentors to assist them in effectively mentoring their mentees. Here, we describe the development of a survey instrument built upon traditional mentoring models that includes a critical race theory framework to capture criteria that are essential for effective mentoring of students from underrepresented populations. The survey instrument described here is designed to specifically target culturally Deaf students who draw from Deaf community cultural wealth. In designing this instrument, we asked two research questions:

1. Does a theoretical mentoring framework that combines traditional capitals with critical race theory explain the different experiences that deaf mentees have had with different mentors? Do the capitals cluster into factors that explain 
the variability that deaf mentees have in their mentoring experiences?

2. Does the hearing status of the mentor, or the familiarity of the mentor with deaf individuals, affect the mentoring experiences of deaf mentees?

While our work focuses on Deaf community cultural wealth, the framework presented here could be adapted for community cultural wealth for students from other underrepresented groups in STEM. In particular, recent work by Haeger and Fresquez (2016) recognizes the critical need for culturally relevant mentoring to better support underrepresented students' research experiences.

\section{SURVEY DEVELOPMENT}

\section{Institutional Research Board}

This study was granted exemption according to 45 CFR $\S 46$ on November 23, 2014, by the Gallaudet University IRB. It was assigned PJID \#2514.

\section{Survey Theoretical Framework}

This framework includes "traditional" capitals: academic and discipline knowledge, which is one's accumulation of educational and academic experiences that allow one to become a successful scientist in academia, and social capital, which is networks of people and social resources (Thompson et al., 2015). Second, and uniquely, this framework includes community cultural wealth, which is a group of capitals that minority individuals acquire from their communities that help them succeed in privileged environments (Yosso, 2005; Hauser, 2013). Aspirational capital is the role models from that community. Community capital is the support of the community, the benefits of language and culture, and the mores and cultural life script of the community. Navigational capital is the skill of maneuvering through institutions created by the dominant group. Resistance capital is the passion for social justice and the strength to challenge systemic inequities. Community cultural wealth is an integral component of Hauser's (2013) STEM mentoring model for Deaf students. We refer readers to Table 1 for additional details on each of the capitals in the framework.

The survey instrument specifically targeted culturally Deaf mentees, usually denoted by a capital D. Culturally Deaf individuals belong to the Deaf community and Deaf culture, which is a distinct subculture. Deaf individuals use American Sign Language (ASL) as their principal language, at least at home and with deaf friends. This is in contrast to individuals with hearing loss who are not culturally Deaf. These individuals may have the same amount of hearing loss, but usually identify themselves as "hearing impaired," were raised orally, do not know ASL, and do not participate in the Deaf community. However, because our study included different categories of people with hearing loss, not all of whom were necessarily culturally Deaf, we use the lowercase "deaf" throughout to refer to all individuals with hearing loss.

\section{Overview of Survey Development: Survey Validity}

We developed the Deaf Mentoring Survey (DMS) through an iterative process that included several rounds of refinement and two rounds of surveying. We began by examining previously validated survey instruments for mentoring effectiveness. We used multiple means of content validity and construct validity as recommended by Worthington and Whittaker (2006). Measures of content validity included building upon previously validated surveys and the mentoring literature, using a focus group of expert deaf faculty to evaluate survey items, and interviews with deaf STEM faculty and students. Construct validity included statistical analyses to evaluate the relationships between survey items and demonstrating consistency between survey results and the published literature.

\section{Survey Item Development}

We reviewed validated scales from other surveys in the published literature to borrow content for our survey. These were the Project Ownership Survey (Hanauer and Dolan, 2014); the Mentorship Effectiveness Scale (Berk et al., 2005), designed for mentoring in clinical medicine; the Mentoring Competency Assessment (MCA; Fleming et al., 2013), designed for medical research mentoring; and the Advisory Working Alliance Inventory (Schlosser and Gelso, 2001, 2005), designed for assessing advisor-advisee relationships in graduate school. We selected items from these validated surveys and then assigned them to capitals within our theoretical framework as described below. All of the items taken from these surveys were unsurprisingly assigned to traditional capitals, predominantly academic/discipline capital. Many of the items from these surveys were similar to one another. The rest of the pilot survey design was an iterative process: the three authors developed additional items for capitals where needed, independently reviewed the assignment of each item to each capital within the theoretical framework, and reviewed and modified items for clarity and content validity. Disagreements about assignments of items to capitals were resolved by consensus until each item could be uniquely and consistently assigned to the same capital.

\section{Expert Focus Group}

To confirm content validity, we ensured that that the draft survey items were unambiguous to the target community of deaf mentees in STEM fields (Worthington and Whittaker, 2006). A deaf coauthor (D.C.B.) led a focus group to solicit expert feedback on our draft items. This focus group consisted of eight deaf faculty from a variety of STEM fields. Focus group participants were shown the pilot survey items and asked three questions: 1) Do the items match their capital?, 2) Are the items clear and unambiguous?, and 3) Are we missing anything? Free discussion was encouraged. The focus group reached consensus after discussion. The draft items were further revised based on feedback from the focus group.

\section{Pilot Item Testing}

We piloted the items in a survey of deaf individuals at all levels of education who had a previous mentored STEM research experience at the undergraduate, graduate, or postdoctoral level. To recruit survey participants, we asked colleagues from multiple institutions who had previously mentored deaf students to share the names and email addresses of the students they had mentored. We also contributed the names and email addresses of students they had mentored.

The pilot survey included 52 items focused on mentoring. The order and categorization of the items were fully randomized, so as to not influence factor analysis or inflate measures of 
TABLE 1. Capitals in our theoretical framework

\begin{tabular}{|c|c|c|c|c|}
\hline & Capital & Definitions & Examples & References \\
\hline \multirow{3}{*}{ 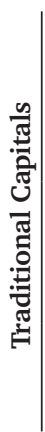 } & Academic capital & $\begin{array}{l}\text { One's accumulation of educational and } \\
\text { academic experiences that allow one to } \\
\text { become a successful scientist in academia. }\end{array}$ & $\begin{array}{l}\text { How to navigate academic milestones, } \\
\text { understand the process of peer } \\
\text { review, grant preparation, confer- } \\
\text { ence presentation, and publication } \\
\text { of scholarship. }\end{array}$ & $\begin{array}{l}\text { Hauser, 2013; Thompson } \\
\text { et al., } 2015\end{array}$ \\
\hline & Discipline capital & $\begin{array}{l}\text { The set of discipline-specific paradigms, } \\
\text { including facts, beliefs, and values, related } \\
\text { to conducting research. }\end{array}$ & $\begin{array}{l}\text { Laboratory skills, knowledge of specific } \\
\text { terminology, and the knowledge } \\
\text { required for collecting and analyzing } \\
\text { data. }\end{array}$ & $\begin{array}{l}\text { Hauser, 2013; Thompson } \\
\quad \text { et al., } 2015\end{array}$ \\
\hline & Social capital & $\begin{array}{l}\text { Networks of people and social resources and } \\
\text { the social skills needed to navigate these } \\
\text { networks and use these resources. }\end{array}$ & $\begin{array}{l}\text { A good mentor teaches academic social } \\
\text { skills and behavior. }\end{array}$ & $\begin{array}{l}\text { Hauser, 2013; Thompson } \\
\text { et al., } 2015\end{array}$ \\
\hline \multirow{4}{*}{ 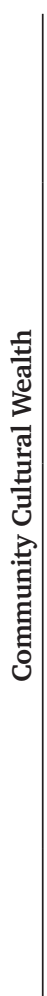 } & Navigational capital & $\begin{array}{l}\text { The knowledge and skills of how to maneuver } \\
\text { through institutions and systems created } \\
\text { by the dominant group and succeed } \\
\text { despite systematic oppression. }\end{array}$ & $\begin{array}{l}\text { Deaf role models share their knowledge } \\
\text { of how to obtain accommodations } \\
\text { and navigate graduate school, } \\
\text { conferences, and other aspects of } \\
\text { science and academia. }\end{array}$ & $\begin{array}{l}\text { Yosso, 2005; Lee, 2006; } \\
\text { Williamson, 2007; } \\
\text { Listman et al., 2011; } \\
\text { Hauser, } 2013\end{array}$ \\
\hline & Aspirational capital & $\begin{array}{l}\text { The resiliency or the ability to succeed against } \\
\text { the odds. Aspirational capital is possible in } \\
\text { the absence of visible role models and } \\
\text { even in the absence of success; for } \\
\text { example, Yosso describes how Latino } \\
\text { families traditionally emphasize education } \\
\text { though their educational levels are lower } \\
\text { than those of the general population. }\end{array}$ & $\begin{array}{l}\text { Role models who share stories about } \\
\text { their own successes provide } \\
\text { aspirational capital. In deaf } \\
\text { education, it has long been thought } \\
\text { that deaf role models have a positive } \\
\text { influence on deaf students. }\end{array}$ & $\begin{array}{l}\text { Treisman, 1992; Yosso, } \\
\text { 2005; Hauser, 2013; } \\
\text { Treisman, } 2013\end{array}$ \\
\hline & Community capital & $\begin{array}{l}\text { This capital combines Yosso's (2005) concepts } \\
\text { of familial capital and linguistic capital. } \\
\text { Community capital is the history of the } \\
\text { community, its memory, cultural } \\
\text { intuitions, and language. Members of a } \\
\text { cultural community often follow a } \\
\text { "cultural life script" or cultural norms. } \\
\text { This cultural life script allows members to } \\
\text { become successful, overcome oppression, } \\
\text { develop advocacy skills, and withstand } \\
\text { discrimination. }\end{array}$ & $\begin{array}{l}\text { For the Deaf community, this includes } \\
\text { knowledge of ASL and the ability to } \\
\text { converse and understand two } \\
\text { different languages and cultures. } \\
\text { This connection provides resources } \\
\text { and reduces isolation. The Deaf } \\
\text { cultural life script includes } \\
\text { expectations that they will partici- } \\
\text { pate in sports, attend a school for } \\
\text { the deaf, and form networks in the } \\
\text { Deaf community. }\end{array}$ & $\begin{array}{l}\text { Yosso, 2005; Hauser, 2013; } \\
\text { Clark and Daggett, } 2015\end{array}$ \\
\hline & Resistance capital & $\begin{array}{l}\text { The passion for social justice and the strength } \\
\text { to challenge systemic inequities. Research } \\
\text { shows that resistance capital can be } \\
\text { taught. }\end{array}$ & $\begin{array}{l}\text { Resistance capital recognizes that one } \\
\text { does not place the blame for failure } \\
\text { on the individual, but rather analyzes } \\
\text { the system to understand failures. }\end{array}$ & $\begin{array}{l}\text { Treisman, 1992, 2013; } \\
\text { Yosso, 2005; Hauser, } \\
\text { 2013; }\end{array}$ \\
\hline
\end{tabular}

reliability (Goodhue and Loiacono, 2002). Participants were asked to respond to a Likert scale from zero to six, eliminating the neutral position, which is uninformative and encourages satisficing (Sturgis et al., 2014). Zero indicated strongly disagree, one indicated somewhat disagree, two indicated slightly disagree, three indicated slightly agree, four indicated somewhat agree, and five indicated strongly agree. Six was used to indicate when a statement was not applicable (N/A). All of the survey items were positively keyed. This decision was based on research showing that the inclusion of negatively keyed items creates an artifactual factor during subsequent factor analysis (Schmitt and Stults, 1985).

We included nine demographic items to collect the participant's (mentee's) gender, race/ethnicity, hearing status, method of communication, involvement with the Deaf community, parents' education level, and career level at the time of the mentoring relationship, and the mentor's hearing status and familiarity with the Deaf community. The gender options were "female," "male," and "other" with a write-in box. Ethnicity options allowed for selection of multiple ethnicities and "other" with a write-in box.

The pilot survey was distributed to 92 potential participants via SurveyMonkey (SurveyMonkey, Palo Alto, CA; pilot survey not shown). Nonresponders were reminded once by email 2 weeks later. Fifty-six pilot surveys were collected for a response rate of $60.9 \%$. Eighteen percent $(n=10)$ of participants filled out the pilot survey a second time, evaluating their relationship with a second mentor, providing us with a final data set of 66 responses. This is a large data set for our target demographic of deaf scientists due to the rarity of deaf scientists, as discussed in the Introduction, and also because there is no direct way to reach out to all deaf scientists.

Analysis of the responses from the pilot survey revealed three issues. First, mentees who self-identified as hard of 
hearing ( $11 \%$ of responses; $n=7$ ) or hearing impaired ( $5 \%$ of responses; $n=3$ ) overwhelmingly replied "not applicable" (N/A) to items about community cultural wealth, probably because they were not culturally Deaf, and these items were therefore not relatable to their life experiences. Second, there were N/A or blank responses scattered throughout all but four items of the pilot survey, indicating satisficing, perhaps from survey fatigue. Third, correlation analysis (i.e., the $R$ matrix) of the pilot survey responses showed strong multicollinearity between the many items relating to traditional capitals. Consequently, for the second survey, we made several changes. To ensure that it was relatable, we decided that the revised survey would only be distributed to deaf respondents and not those who had self-identified as or hearing impaired or hard of hearing. To reduce satisficing, we refined the items to be concise and clearer, based on what we learned from interviews and cognitive interviews (described below), and we removed the N/A option for all items and instead provided text boxes for comments. Finally, to reduce multicollinearity and further reduce satisficing, we shortened the survey by removing many of the items about traditional capitals.

\section{Interviews}

Together, two coauthors (D.C.B. and C.G.) interviewed eight deaf individuals at all levels of education who had a previous STEM mentored research experience at the undergraduate $(n=2)$, graduate $(n=3)$, or postdoctoral $(n=3)$ level. The semistructured, individual interviews were conducted in ASL and focused on understanding:

1. What do successful research mentors of deaf students do?

2. What is successful research mentoring for deaf studentswhat does that look like?

Participants were encouraged to explain their experiences with mentored research. Questions focused on what their research mentors did that was helpful and not helpful for them to be successful as a deaf person in STEM, as well as things their research mentors could have done that would have been helpful. Faculty participants were also asked what they do as faculty to help deaf students to be successful in STEM. Interviews were 30-45 minutes and video-recorded.

After each interview, the two coauthors immediately discussed the participant's responses, made extensive notes, and reviewed video recordings when needed. The authors compared participants' responses with survey items to identify critical missing items related to mentoring. The authors also used participants' responses to further establish content validity. We constructed additional survey items and revised and removed some items based on interviewees' frequently occurring responses. For example, we removed several academic and discipline capital items based on the relative unimportance of the themes expressed in the items to interviewees. In addition, the lack of variability in individual experiences in the academic and discipline capital items corroborated the multicollinearity between these items that we detected on the pilot survey. Importantly, interviews uncovered several consistent, important themes: participants described experiencing an "invisible barrier," which kept them from fully communicating and interacting with laboratory members; participants did not have access to "water-cooler talk"; and participants discussed the importance of their mentors exposing them to the "everyday life of a scientist."

During the cognitive interviews, we noted that, while answering questions, interviewees would often, and without warning, jump from talking about one mentoring relationship to another. We realized that pilot survey participants may have unintentionally ambiguated between mentoring experiences in their responses. Therefore, in our second survey, participants were asked to name a specific mentor or to provide an alias for that mentor. The provided mentor's name or alias was embedded within many of individual items (a function conveniently provided by SurveyMonkey) so as to continually remind the participant to strictly answer the items in the context of one particular mentoring relationship.

\section{Cognitive Interviews}

We recruited student volunteers for cognitive interviews $(n=2)$. The goal of cognitive interviewing was to walk through the survey and determine whether survey respondents comprehended and responded to items as intended (Willis, 2004). Cognitive interviews allowed us to identify problems with item wording and correct these issues before survey distribution. The cognitive interviews were conducted by two coauthors (D.C.B. and C.G.). Student interviewees were asked to take the survey while "thinking aloud" (in ASL), explaining their reasoning for their selected responses to the survey, and reacting to confusing item wording. The two coauthors listened and took detailed notes. Responses were used to inform further survey item revisions, including removing jargon and simplifying item sentences.

\section{Revised Survey Distribution}

The revised survey was distributed to 81 potential participants via SurveyMonkey. Recruitment methods were identical to the pilot survey recruitment, with the exception that we did not reach out to potential participants who had self-identified as hearing impaired or hard of hearing in the pilot survey. Nonresponders were reminded twice by email. Fifty-nine revised surveys were collected for a response rate of $72.8 \%$. Twenty-two percent $(n=13)$ of participants filled out the survey a second time, evaluating their relationship with a second mentor, providing us with a final data set of 71 responses reflecting 71 mentoring experiences (see Tables 2 and 3). As with the pilot survey, this is a large data set for our target demographic of deaf scientists.

The revised survey included a total of 35 items focused on mentoring. The demographic questions asked were identical to the pilot survey, except that we omitted the question about the mentee's involvement with the Deaf community, since we found it redundant with our questions about their self-identified hearing status and language preference. We asked for a mentor name or alias, and this name or alias was embedded into many of the survey items, as noted earlier. There was no option given for not applicable (N/A); however, participants could add more information in free-response questions, which were evaluated when the survey was analyzed. None of the free-response answers caused us to reassign an answer to an item or eliminate a response. The organization and structure of the survey was otherwise identical to the pilot survey. 
TABLE 2. Demographics of survey participants ( $n=58$ mentees)

\begin{tabular}{|c|c|c|}
\hline Characteristic & $n^{\mathrm{a}}$ & $\%$ \\
\hline \multicolumn{3}{|l|}{ Gender } \\
\hline Female & 27 & 46.6 \\
\hline Male & 30 & 51.7 \\
\hline Transgender & 1 & 1.7 \\
\hline \multicolumn{3}{|l|}{ Ethnicity } \\
\hline African American & 4 & $7 .($ \\
\hline Asian American & 4 & $7 .($ \\
\hline Latino/Latina & 5 & 8.8 \\
\hline Native American & 2 & 3.5 \\
\hline Pacific Islander/Hawaiian & 1 & 1.8 \\
\hline White/European & 48 & 84.2 \\
\hline Prefer not to respond & 1 & 1.8 \\
\hline \multicolumn{3}{|l|}{ Identified hearing status } \\
\hline Deaf & 56 & 96. \\
\hline Hearing impaired & 0 & 0. \\
\hline Hard of hearing & 2 & 3.4 \\
\hline \multicolumn{3}{|l|}{ Preferred method of communication } \\
\hline ASL & 51 & 87.5 \\
\hline Signed English & 1 & 1.7 \\
\hline Spoken English & 6 & 10.3 \\
\hline \multicolumn{3}{|l|}{ Parents' college education } \\
\hline Both parents attended college & 35 & 60.3 \\
\hline Only one parent attended college & 11 & 19. \\
\hline Neither parent attended college & 12 & 20.7 \\
\hline \multicolumn{3}{|c|}{$\begin{array}{l}\text { aThe } n \text { is greater for mentoring experiences }(n=71) \text { than for mentees }(n=58) \\
\text { because some mentees took the survey more than once, reporting on more than } \\
\text { one mentoring experience; this is why numbers shown here may not match num- } \\
\text { bers reported elsewhere. } \\
\text { bFifty-seven participants responded to the ethnicity question. The total for ethnici- } \\
\text { ties is greater than } n=57 \text { because some mentees identified more than one ethnicity. }\end{array}$} \\
\hline
\end{tabular}

\section{Software}

All statistical analyses were conducted using IBM SPSS Statistics version 23 on Mac OS X.

\section{RESULTS}

\section{Factor Analysis}

We used exploratory factor analysis to determine the underlying latent structure and address the first hypothesis. Maximum-likelihood factor analysis would not have been a good approach, because item responses were not normally distributed. Therefore, we conducted principal-axis factor analysis with oblique rotation (direct oblimin with Kaiser normalization) on the 35 survey items. The initial factor analysis revealed four neat factors. However, the determinant of the correlation matrix of our initial analysis showed multicollinearity. Therefore, we iteratively eliminated items over multiple rounds of factor analysis to reduce collinearity and improve the determinant. Items were eliminated objectively using these criteria: if they had many correlations $>0.8$, few correlations $<0.3$, or exhibited significant factor cross-loading $>0.3$ (Worthington and Whittaker, 2006; Field, 2013). We continued to remove items iteratively until the determinant reached $7.45 \times 10^{-6}$, indicating an acceptable level of collinearity (Field, 2013).

On the final iteration, the Kaiser-Meyer-Olkin measure verified a "meritorious" level of sampling adequacy for the analysis
TABLE 3. Characteristics of mentors and mentoring experiences ( $n=71$ mentoring experiences)

\begin{tabular}{lrr}
\hline Characteristic & $\boldsymbol{n}$ & $\%$ \\
\hline Mentor's hearing status & & \\
$\quad$ Deaf & 24 & 33.8 \\
$\quad$ Hearing impaired & 1 & 1.4 \\
Hard of hearing & 2 & 2.8 \\
$\quad$ Hearing & 44 & 62.0 \\
Mentor's familiarity with Deaf people & & \\
A member of the Deaf community & 39 & 54.9 \\
Some experience with Deaf people & 13 & 18.3 \\
$\quad$ Little or no experience with Deaf people & 19 & 26.8 \\
Mentee's career level during mentoring experience & \\
$\quad$ High school & 0 & 0.0 \\
Undergraduate & 37 & 52.1 \\
Postbaccalaureate & 4 & 5.6 \\
Graduate school & 25 & 35.2 \\
$\quad$ Postdoctoral & 5 & 7.0 \\
\hline
\end{tabular}

with a $\mathrm{KMO}=0.819$ (Worthington and Whittaker, 2006; Field, 2013). Communalities for individual items on the final iteration also supported adequate sampling size (mean $=0.691$; range $0.484-0.908$ ), indicating at least a $99 \%$ chance of convergence on the correct factors given the data set size of 71 responses (MacCallum et al., 1999). Bartlett's test of sphericity, which is particularly sensitive with small sample sizes, was highly significant ( $p<0.001$; Worthington and Whittaker, 2006). The first four factors had eigenvalues greater than one and altogether explained $76.8 \%$ of the variance (see Figure 1). We retained four factors based on the agreement between the point of inflexion on the scree plot and Kaiser's criterion of four factors (Figure 1 and Table 4). To test the robustness of our data set to

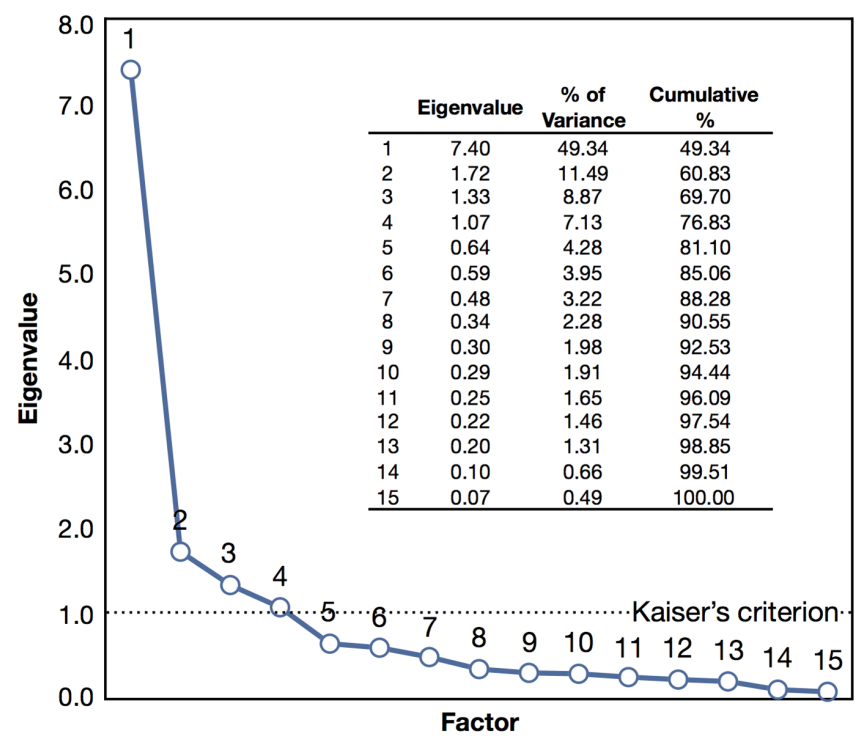

FIGURE 1. Scree plot from exploratory factor analysis. The eigenvalues for each factor are shown. We retained four factors based on the agreement between two commonly used criteria: 1) Kaiser's criterion to retain factors with eigenvalues above 1.0 and 2) the point of inflexion. 


\begin{tabular}{|c|c|c|c|}
\hline & Capital & Mean & SD \\
\hline $\begin{array}{l}\text { 1. [Name] helped me better understand science communication (e.g., poster presentations, } \\
\text { platform presentations, authorship, grant applications, and peer review). }\end{array}$ & Academic/discipline & 4.85 & 1.66 \\
\hline 2. I felt like I had full access to academic knowledge. & Academic/discipline & 5.18 & 1.36 \\
\hline 3. [Name] increased my knowledge of my discipline. & Academic/discipline & 5.37 & 1.15 \\
\hline 4. [Name] taught me how to work independently. & Academic/discipline & 5.15 & 1.36 \\
\hline 5. [Name] taught me how to use the tools, techniques, and methods of my field. & Academic/discipline & 5.30 & 1.29 \\
\hline 6. [Name] exposed me to the everyday life of a scientist. & Academic/discipline & 5.23 & 1.38 \\
\hline 7. [Name] helped me improve my science writing skills. & Academic/discipline & 4.86 & 1.58 \\
\hline 8. I had a good professional relationship with [Name]. & Social & 5.31 & 1.23 \\
\hline 9. I felt comfortable discussing personal things with [Name]. & Social & 4.41 & 1.75 \\
\hline 10. [Name] encouraged me to develop working relationships with others in my lab. & Social & 5.06 & 1.31 \\
\hline 11. [Name] encouraged me to meet other people working in my field. & Social & 4.80 & 1.54 \\
\hline 12. I had no problems communicating with others in [Name]'s lab. & Social & 5.13 & 1.40 \\
\hline 13. I was included in conversations in this lab. & Social & 5.07 & 1.37 \\
\hline 14. [Name] and I have stayed in touch, or will stay in touch with one another for many years. & Social & 4.76 & 1.53 \\
\hline 15. [Name] made sure my communication needs were met. & Navigational & 5.20 & 1.32 \\
\hline 16. I received all the accommodations I needed. & Navigational & 5.14 & 1.31 \\
\hline 17. [Name] gave me career advice. & Navigational & 4.86 & 1.45 \\
\hline $\begin{array}{l}\text { 18. [Name] taught me how to ask for the accommodations I need now and in the future } \\
\text { (e.g., at professional meetings, in graduate programs, etc.). }\end{array}$ & Navigational & 3.85 & 1.79 \\
\hline 19. [Name] discussed with me how to work with interpreters or real-time captioning (CART). & Navigational & 3.68 & 1.80 \\
\hline 20. [Name] challenged me to try new things. & Aspirational & 5.08 & 1.26 \\
\hline 21. [Name] helped my confidence. & Aspirational & 4.80 & 1.59 \\
\hline 22. [Name] gave me a role model(s) to look up to. & Aspirational & 4.86 & 1.62 \\
\hline 23. [Name] taught me how to be successful in science. & Aspirational & 5.03 & 1.31 \\
\hline 24. I was exposed to deaf scientists while in [Name]'s lab. & Aspirational & 4.15 & 1.96 \\
\hline 25. [Name] helped me to see myself as a scientist. & Aspirational & 5.18 & 1.33 \\
\hline 26. [Name] encouraged me to have deaf friends. & Community & 4.35 & 1.58 \\
\hline 27. [Name] encouraged me to participate in the deaf community. & Community & 4.10 & 1.74 \\
\hline 28. [Name] encouraged me to balance work and life. & Community & 4.65 & 1.61 \\
\hline 29. [Name] had a positive attitude about ASL. & Community & 5.42 & 1.01 \\
\hline 30. [Name] was aware that deaf people are often stronger in one language than another. & Community & 4.96 & 1.34 \\
\hline 31. [Name] encouraged me to stand up for myself. & Resistance & 4.75 & 1.55 \\
\hline 32. [Name] had a positive attitude about deaf people. & Resistance & 5.48 & 1.11 \\
\hline 33. [Name] thought it was important that my coworkers understand Deaf culture. & Resistance & 4.58 & 1.60 \\
\hline 34. [Name] thought that hearing people should meet deaf people halfway. & Resistance & 4.93 & 1.43 \\
\hline 35. [Name] thought that deaf people shouldn't need to work any harder than hearing people. & Resistance & 4.27 & 1.54 \\
\hline
\end{tabular}

our statistical approach, we repeated this analysis, first using principal-axis factoring with orthogonal rotation and then principal component analysis. These approaches yielded the same four factors with the same items in each factor (unpublished data).

\section{Characteristics of the Four Factors on the DMS}

The final DMS includes 15 items (Table 5). The factor analysis results showed that the capitals in our theoretical framework factored neatly, indicating strong support for this theoretical framework.

The Being a Scientist factor included five items. These items contained all of the traditional capital items (academic/discipline and social capital), plus items for aspirational capital from community cultural wealth. This factor appears to capture what mentors are traditionally expected to provide to their mentees to train them as scientists. Mentors taught academic and discipline content and the social skills needed to succeed in a science career. Based on our factorization, mentors also provided encouragement. This is probably why aspirational capital items also factored with this otherwise traditional factor. The agreement between this factor and our theoretical model is very high: in the first iteration of factor analysis with 35 items, all 16 of the items in this first factor belonged to the traditional capitals or aspirational capital (unpublished data).

The Deaf Community Capital factor contained four of the five community capital items from community cultural wealth. The focus of this factor was awareness of the importance of the Deaf community for personal and emotional support for deaf individuals and an understanding of and respect for ASL.

The Asking for Accommodations factor included navigational capital items, related to learning how to ask for accommodations. One item was about whether the mentor discussed with the mentee about how to work with ASL interpreters or real-time captioning. The second item was about whether the mentor taught the mentee how to ask for the accommodations, such as at professional conferences. 
TABLE 5. Factor analysis: pattern matrix and regression coefficients of final survey

\begin{tabular}{|c|c|c|c|c|c|c|}
\hline & & \multirow[b]{3}{*}{ Capital } & \multicolumn{4}{|c|}{ Factor } \\
\hline & & & $\begin{array}{l}\text { Being a } \\
\text { Scientist }\end{array}$ & $\begin{array}{l}\text { Deaf Community } \\
\text { Capital }\end{array}$ & $\begin{array}{c}\text { Asking for } \\
\text { Accommodations }\end{array}$ & $\begin{array}{l}\text { Communication } \\
\text { Access }\end{array}$ \\
\hline & & & $\alpha=0.89$ & $\alpha=0.86$ & $\alpha=0.80$ & $\alpha=0.91$ \\
\hline 20. & [Name] challenged me to try new things. & Aspirational & 0.814 & & & \\
\hline 28 & $\begin{array}{l}\text { [Name] encouraged me to balance work and } \\
\text { life. }\end{array}$ & Community & 0.576 & & & \\
\hline 8. & $\begin{array}{l}\text { I had a good professional relationship with } \\
\text { [Name]. }\end{array}$ & Social & 0.567 & & & \\
\hline 29 & [Name] had a positive attitude about ASL. & Community & & 0.680 & & \\
\hline 19. & $\begin{array}{l}\text { [Name] discussed with me about how to } \\
\text { work with interpreters or CART. }\end{array}$ & Navigational & & & 0.801 & \\
\hline 18. & $\begin{array}{l}\text { [Name] taught me how to ask for the } \\
\text { accommodations I need now and in the } \\
\text { future (e.g., at professional meetings, in } \\
\text { graduate programs, etc.). }\end{array}$ & Navigational & & & 0.739 & \\
\hline 16. & I received all the accommodations I needed. & Navigational & & & & 0.991 \\
\hline 12. & $\begin{array}{l}\text { I had no problems communicating with } \\
\text { others in [Name]'s lab. }\end{array}$ & Social & & & & 0.677 \\
\hline 15. & $\begin{array}{l}\text { [Name] made sure my communication needs } \\
\text { were met. }\end{array}$ & Navigational & & & & 0.536 \\
\hline
\end{tabular}

Although the law requires accommodations, they are usually not provided unless requested. Even when accommodations are asked for, institutions and organizations are wary of the cost and therefore reluctant to provide them. Therefore, to be successful as a deaf scientist, one must become a skilled negotiator. Asking for accommodations is not limited to only professional conferences. Deaf undergraduate students also need to ask for accommodations for smaller events that the greater community takes for granted, including attending laboratory group meetings, classes, invited campus speakers or lecture series, science club meetings, panels and workshops, and even study groups.

The Communication Access factor included two navigational capital items and two social capital items. This factor reflected whether the mentee felt that he or she had full communication access and full access to information during the mentored research experience. This factor not only reflected formal accommodations such as providing ASL interpreters for the classroom; it also reflected access to informal conversation. During our interviews, several interviewees cited an "invisible barrier" and the lack of access to "water-cooler talk" in some of their mentored research experiences.

\section{Statistical Analyses}

For each response, we calculated scores for each of the four factors by the regression method. Histograms of factor scores showed that factor scores were not normally distributed with calculated skewnesses of at least 2 SDs. Therefore, we used nonparametric tests for all comparisons of factor scores between different groups of mentor or mentee characteristics. Altogether, we made 32 comparisons, indicating that $\sim 1.6$ comparisons would be expected to reach a significance level of $p \leq 0.05$ by chance alone. Figure 2 uses box plots, which are informative yet succinct, to illustrate significant differences in the categories we compared (Nuzzo, 2016).

Gender. In the survey, respondents could choose "female," "male," or "other" with a provided write-in box. Two respondents identified as transgendered. We excluded the transgendered category from analysis, because the sample size was too small for a meaningful comparison, and performed the nonparametric Mann-Whitney test on just females $(n=34)$ and males $(n=35)$ across all four factors. We found no significant differences in scores reported of mentoring relationships based on the mentee's gender $(p=0.573,0.904,0.127$, and 0.614$)$.

Ethnicity. In the survey, respondents could choose multiple ethnicities, including "other" with a provided write-in box. Several mentees identified as both white/European and either Latino/Latina, Native American, or Pacific Islander/Hawai'ian; these were recoded to the underrepresented group. One 

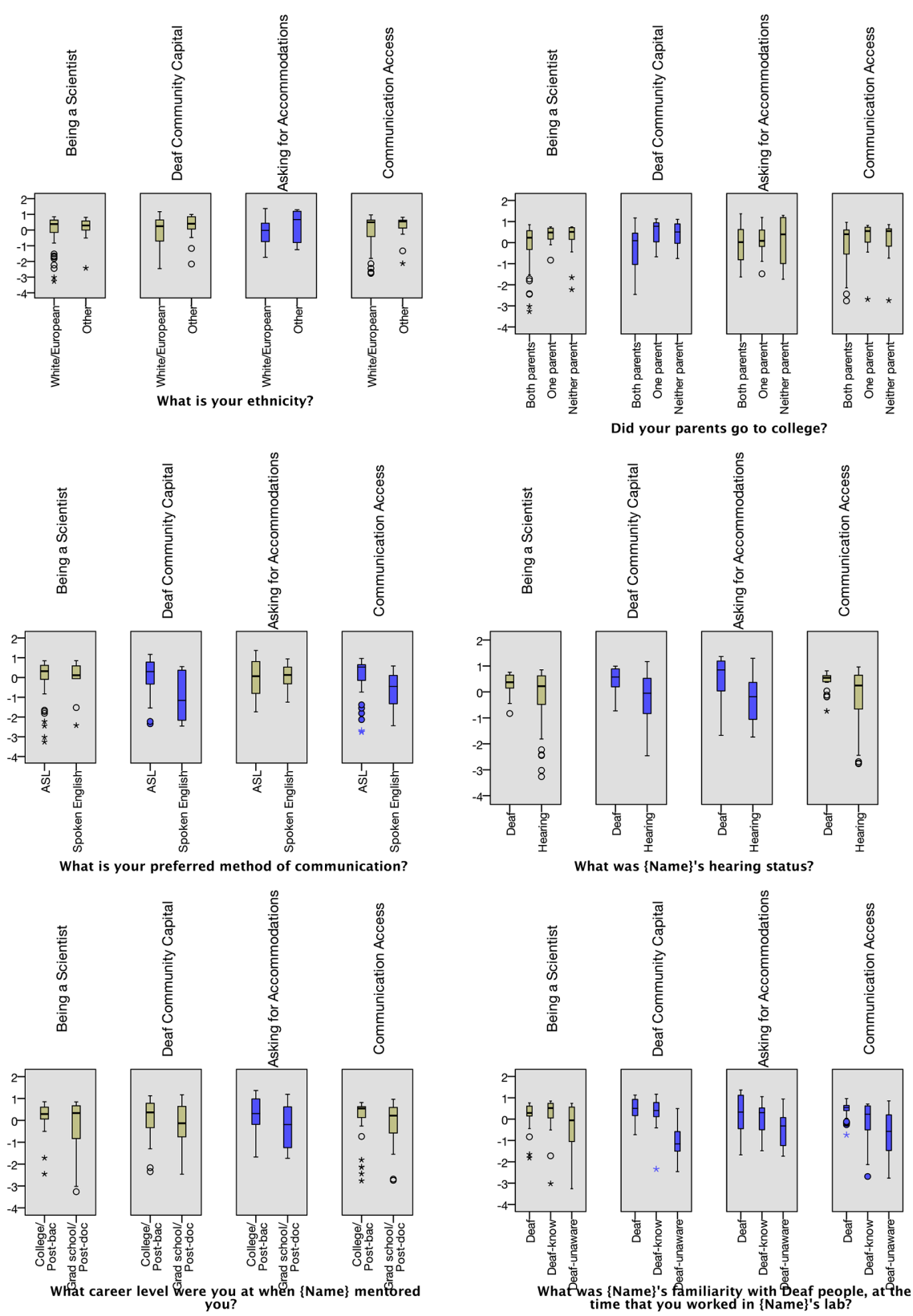

FIGURE 2. Box plots of factor scores with significant differences between groups based on demographic variables $(p<0.05)$. Box plots provide a convenient way to visually compare distributed data across categories (Nuzzo, 2016). Mentee's ethnicity, parents' college education levels, preferred communication method, and career level; and mentor's hearing status and familiarity with deaf people all had significant differences in specific factor scores. There is significant trend between familiarity with deaf people and factor scores. Mentors who are deaf or familiar with deaf people received the highest factor scores for Deaf Community Capital, Asking for Accommodations, and Communication Access.

( $n=10)$ across all four factor scores. These results are visually represented by box plots (Figure 2). We found a significant difference in Communication Access $(p=0.788,0.269,0.044$, and 0.788$)$ scores reported of the mentoring relationship. Figure 2 shows that Communication Access scores were higher in the minority group. We are unable to explain this significant difference. Because $p=$ 0.044 ranks as the least significant of the significant $p$ values over the 32 comparisons done in this study, we think this significance may have occurred by chance and can be disregarded (Glickman et al., 2014).

Mentee's Hearing Status. Sixty-eight responses identified as deaf and three responses identified as hearing impaired. These results are unsurprising because we made an effort to distribute the second survey to deaf individuals. The hearing-impaired category size was too small to allow for meaningful comparison of factor scores by category.

Mentor's Hearing Status and Mentor's Familiarity with Deaf People. Only one response identified a mentor as hearing impaired, and only two responses identified mentors as hard of hearing. The sample sizes for these two categories were too small for meaningful $k$-groups comparisons and were excluded from further analysis. We performed the nonparametric Mann-Whitney test on the two remaining categories, comparing deaf mentors with hearing mentors. These results are visually represented by box plots (Figure 2). We found a highly significant difference in scores reported of mentoring relationships in Deaf Community Capital and Asking for Accommodations $(p=0.193, p=0.013, p<$ $0.001, p=0.132$ ). Deaf mentors received the highest score for Deaf Community Capital, as would be expected. This result therefore internally validates the survey.

For the mentor's familiarity with deaf people, we categorized mentors who are members of the Deaf community as

response identified four different ethnicities and was excluded from testing. Altogether, each of the cultural or ethnic minority responses ranged from $n=6$ to $n=1$, while the white/European group had $n=51$ responses. Because each of these groups was too small for a meaningful $k$-groups comparison, we performed the nonparametric Mann-Whitney test, comparing just whites/ Europeans $(n=51)$ with combined underrepresented minorities
"Deaf," mentors who are presumably hearing but have experience working with Deaf mentees as "Deaf-know," and mentors who have little or no experience with Deaf mentees as "Deaf-unaware." The Deaf-know and Deaf-unaware terms used here are syntactic calques borrowed from ASL.

We performed the nonparametric $k$-independent groups Kruskal-Wallis test comparing all four factor scores across 
Deaf, Deaf-know, and Deaf-unaware categories of mentors. These results are visually represented by box plots (Figure 2). Being a Scientist $(H(2)=5.02, p=0.081)$ scores of mentoring relationships were not significantly affected by the mentor's hearing status. Deaf Community Capital $(H(2)=30.4, p<$ 0.001), Asking for Accommodations $(H(2)=9.25, p=0.010)$, and Communication Access $(H(2)=12.5, p=0.002)$ scores of mentoring relationships were highly significantly affected by the mentor's familiarity with deaf people. Post hoc pairwise comparisons with adjusted $p$ values showed a highly significant difference in Deaf Community Capital scores of mentoring relationships between Deaf versus Deaf-unaware mentors $(p<0.001)$ and Deaf-know versus Deaf-unaware mentors $(p<0.001)$. Likewise, post hoc pairwise comparisons with adjusted $p$ values also showed a highly significant difference in Asking for Accommodations and Communication Access scores of mentoring relationships between Deaf versus Deaf-unaware mentors $(p=0.007 ; 0.001)$, while the other pairwise comparisons did not achieve significance $(p=0.372$, $1.000 ; 0.528,0.382$ ).

The Deaf, Deaf-know, and Deaf-unaware categories can be thought of as an ordered scale from greatest to least familiarity with deaf individuals and involvement in the Deaf community. We therefore performed the nonparametric Jonckheere-Terpstra test to see whether there was a trend in the data. This test showed a highly significant trend for factor scores reported of mentoring relationships for Deaf Community Capital, Asking for Accommodations, and Communications Access $(p<0.001$, $p=0.003, p<0.001$ ).

The mentor's hearing status and the mentor's familiarity with deaf people are overlapping categories. Our analysis shows that familiarity and experience with deaf mentees had a profound impact upon the perceived mentoring relationship for Deaf Community Capital, Asking for Accommodations, and Communication Access. Examination of the box plots in Figure 2 also shows that Being a Scientist scores are also higher, although this relationship did not reach statistical significance. Altogether, this central finding reinforces the published literature showing that deaf mentees have good mentoring relationships when paired with deaf mentors (Hulsebosch and Myers, 2002; Hauser, 2013; Listman, 2013).

Mentee's Career Level at the Time of Mentoring. Of the four career-level options presented, two options were sparse: four respondents identified postbaccalaureate experiences and five respondents identified postdoctoral experiences. The sample sizes for these two categories were too small for meaningful $k$-groups comparison. Therefore, we recoded the four career options into just two categories of career level at the time of mentoring. We performed the nonparametric Mann-Whitney test comparing mentees at a college or postbaccalaureate career level $(n=41)$ with mentees at a graduate school or postdoc career level $(n=30)$. These results are visually represented by box plots (Figure 2). We found a significant difference in scores reported of mentoring relationships for Asking for Accommodations ( $p=0.463,0.119,0.023$, and 0.274 ), in that these scores were higher for mentoring relationships before graduate school.

Given the highly significant difference in Asking for Accommodations between Deaf/Deaf-know and Deaf-unaware mentors, we analyzed whether this was really because the proportion of Deaf/Deaf-know and Deaf-unaware mentoring relationships differed by career level. We found that, for college and postbaccalaureate mentoring relationships, $85.3 \%$ were with Deaf or Deaf-know mentors, while for graduate or postdoctoral mentoring relationships, only $56.7 \%$ were with Deaf or Deaf-know mentors. Therefore, we explain this significant difference in Asking for Accommodations by noting that fewer mentees who responded to our survey had a Deaf or Deaf-know mentor at the graduate and postdoctoral levels.

These results corroborate the fact that a number of NSFfunded Research Experiences for Undergraduates (REU) programs around the country have slots reserved for deaf students. Through experience, the principal investigators running these programs become Deaf-know mentors. In contrast, far fewer opportunities or designated slots exist for deaf students at the graduate or postdoctoral level.

Mentee's Preferred Language for Communication. Only one respondent identified signed English as the preferred language for communication. We excluded this category because it was too small to do a meaningful $k$-groups comparison, and performed the nonparametric Mann-Whitney test comparing just relationships in which ASL $(n=61)$ or spoken English $(n=9)$ was preferred across all four factors. These results are visually represented by box plots (Figure 2). We found a significant difference in scores reported of mentoring relationships in Deaf Community Capital and Communication Access but not in the other two factors ( $p=0.745,0.015,0.881$, and 0.008).

Given the highly significant difference in Deaf Community Capital and Communication Access between Deaf/Deaf-know and Deaf-unaware mentors, we analyzed whether this was really because the proportion of Deaf/Deaf-know versus Deaf-unaware mentoring relationships differed by the mentee's preferred language. Presumably, mentees who prefer ASL might be more inclined to seek mentoring from or be sought out by Deaf/Deaf-know mentors. We found that $80.3 \%$ of mentees who preferred ASL had Deaf/Deaf-know mentors, while only $22.2 \%$ of mentees who preferred spoken English had Deaf/ Deaf-know mentors.

Mentee's Parents' Education Level. We performed the nonparametric $k$-independent groups Kruskal-Wallis test comparing responses in which the mentee revealed that two parents attended college, one parent attended college, or neither parent attended college. These results are visually represented by box plots (Figure 2). We found a significant difference in scores reported of mentoring relationships in Deaf Community Capital $(H(2)=9.63, p=0.008)$ but not in the other factors $(p=0.261$, $0.546,0.357)$. Post hoc pairwise comparisons with adjusted $p$ values showed a significant difference between whether both of the mentee's parents went to college or only one parent went to college $(p=0.023)$. There were no significant differences between the other pairwise comparisons ( $p=0.091,1.000)$.

Given the highly significant difference in Deaf Community Capital between Deaf/Deaf-know and Deaf-unaware mentors, we analyzed whether the proportion of Deaf/Deaf-know and Deaf-unaware mentoring relationships differed by the mentee's parents' education levels. When both mentees' parents went to college, $65.9 \%$ of these mentees chose Deaf/Deaf-know 
mentors; when only one mentee's parent went to college, $83.3 \%$ of these mentees chose Deaf/Deaf-know mentors; and when neither parent went to college, $86.7 \%$ of these mentees chose Deaf/Deaf-know mentors (Figure 2). We are unable to explain this difference, especially since our data do not show a trend between increasing parental education and decreasing Deaf Community Capital. Our current data set does not allow us to explore why this difference may exist. However, it is hoped that future work, as described in the Discussion, will uncover the reason(s).

\section{Reliability Analysis}

Cronbach's alpha was calculated individually for factor scores, which were recalculated by item averaging, just as the survey would be used in downstream applications. Cronbach's test indicated high reliability for all four factors $(\alpha=0.89,0.86$, 0.80 , and 0.91 , respectively).

\section{DISCUSSION}

Our work provides a framework for improving mentoring of underrepresented students by leveraging community cultural wealth. Disabled individuals, women, and individuals from cultural and ethnic minorities continue to be underrepresented in STEM. Because mentoring has already been shown to be a highly effective intervention, especially in these groups, the goal of any STEM program should be to capitalize upon mentored undergraduate research experiences. Our survey may help this underrepresentation problem by capturing meaningful information about mentoring relationships with deaf students. This same theoretical framework could be used to adapt this survey for other underrepresented groups by devising items that fit that group's community cultural wealth.

Our first research question asked whether our theoretical framework, which was composed of traditional capitals, consisting of academic, discipline, and social capitals, combined with community cultural wealth, could explain the various research experiences reported by mentees. We answered this question by performing exploratory factor analysis on our survey results. The analysis, unexpectedly, revealed that the traditional capitals did not segregate into latent variables as expected. Instead, they conferred together as our first factor, Being a Scientist. As we described above in Factor Analysis, we rigorously tested the factor convergence and obtained the same four factors regardless of our approach. We initially thought that social capital would segregate independently, because not all mentors are equally socially inclined, but this was not the case. Our results suggest that even mentors who are not socially inclined still confer social capital. We were also surprised that aspirational capital, which is a component of community cultural wealth, segregated with the traditional capitals rather than with other community cultural wealth capitals. We interpreted this to mean that good mentors provide encouragement; the aspirational capital items in our survey may have been difficult for respondents to conceptually separate from the aspirational capital specific to minority communities. The other community cultural wealth capitals, on the other hand, neatly segregated into three additional factors: Deaf Community Capital, Asking for Accommodations, and Communication Access.
Our second research question was whether mentoring was more effective when deaf mentees were paired with Deaf or Deaf-know mentors, as supported by past research (Hulsebosch and Myers, 2002; Hauser, 2013; Listman, 2013). At Gallaudet, the recent pairing of deaf undergraduate students with deaf mentors has resulted in a nearly fourfold increase in deaf students matriculating into graduate programs in STEM (D. C. Braun and C. M. Solomon, personal communication). Likewise, Hauser and colleagues at Rochester Institute of Technology report success with this approach in matriculating deaf mentees into graduate programs in psychology, social sciences, and medicine (P. C. Hauser, personal communication). Historically, most mentoring relationships for deaf mentees have been with a Deaf-unaware hearing mentor, and many of these relationships have had documented problems with communication barriers, cultural differences between the mentee and the mentor, and/ or not realizing that a deaf mentee needs accessibility and advocacy (Anscombe, 2007; Woodcock et al., 2007; Listman, 2013; Solomon et al., 2013).

Our results show that Being a Scientist scores of mentoring relationships did not vary significantly depending on whether the mentor was Deaf or familiar with the Deaf community, although these scores were slightly higher with Deaf or Deafknow mentors. However, Deaf Community Capital, Asking for Accommodations, and Communication Access were all highest when mentees were paired with mentors who were Deaf or Deaf-know. These differences were highly statistically significant, and they support our hypothesis and corroborate previous research (Hulsebosch and Myers, 2002; Hauser, 2013; Listman, 2013).

Our results suggest that it may be the lack of cultural awareness and communication barriers, and not the mentor's hearing status per se, that are responsible for the frequently reported disconnect between deaf mentees and their Deaf-unaware hearing mentors. Similarly, Haeger and Fresquez (2016) report that underrepresented students who felt least supported by their mentors rated their mentors as less culturally relevant. In our study, deaf mentees felt that they benefited more when their hearing mentor was familiar with Deaf culture-almost as much as when their mentor was deaf.

We believe that the critical race theory framework used in the DMS may be effective with other underrepresented groups. For this to be accomplished, the community cultural wealth survey items in the DMS would need to be replaced with items that reflect the community cultural wealth of the target underrepresented group. The Deaf community was a good model for this framework, because the Deaf community has its own language, schools, clubs and organizations, social network, and culture. The Deaf community also voluntarily maintains some isolation from the majority (hearing) culture. Most, if not all, other underrepresented groups have forms of community cultural wealth. Latino/as and Native Americans, for example, are often bilingual and bicultural. Even women and sexual minorities possess less explicit forms of community cultural wealth. Awareness of these capitals might improve mentoring with these groups.

If further studies identify community cultural wealth as important for other underrepresented groups, then cultural awareness training of research mentors about specific communities may be a holistic solution for the problem of 
underrepresentation of disabled individuals, women, and cultural and ethnic minorities in STEM and in other fields. For relatively rare minorities such as deaf students, online training modules and resources could be developed, although if deaf students were proportionately represented, most universities would have at least several deaf students.

\section{Recommendations for Mentors/Programs and Downstream Application of the DMS}

On the basis of our results, we offer several recommendations for mentors of deaf students. First, we recommend that mentors working with deaf mentees be aware of the community capital that the Deaf community offers. We suggest that mentors encourage their deaf mentees to make or maintain connections with the local Deaf community and their families and friends. Mentees may benefit from community support they receive, which may in turn lead to a more successful research experience. This community support may take multiple forms, including: advice to develop self-advocacy skills; networking opportunities; and knowledge of local resources available (Yosso, 2005; Clark and Daggett, 2015). Further, community involvement can provide emotional support. Deaf mentees (who may be the only deaf individuals in their particular research environments) may feel less isolated as a result of revitalizing camaraderie that comes from socializing with those who know one's culture and language. Other recent research also recognizes the significant positive impact of socioemotional mentoring and culturally relevant mentoring with underrepresented students' research experiences (Haeger and Fresquez, 2016). Finally, in our interviews, participants revealed that some understanding of and/or a positive attitude about ASL made them feel more welcome.

Mentors should offer support to their deaf mentees to be sure they receive necessary requested accommodations, such as interpreting services or real-time captioning. To do this, mentors should become familiar with their institution's disability services. Accessing accommodations is sometimes complicated (Anscombe, 2007; Woodcock et al., 2007; Wilson et al., 2011; Hauser, 2013). Becoming familiar with how this system works can be useful for mentors to share this information with mentees. This may be particularly useful if mentees are short-term visitors at the institution, such as interns in an REU summer program. Additionally, mentors may have more institutional leverage than a student in ensuring that accommodations are met.

Mentors should also consider communication access in the research environment to make sure the environment is as accessible as possible. Does the mentee have full access to information? Is the mentee able to communicate well with everyone in the research environment? Mentors should ask their mentees what works for them, to understand individual preferences. We also encourage mentors who are hearing to reflect on their privilege (for a good discussion on recognizing privilege gaps between faculty and students, see Killpack and Melón, 2016). For most people who are hearing, this identity only becomes salient if they enter into the Deaf community without fluency in ASL and thus become "impaired" in communication. As a result of this experience, hearing people come to understand more of what it means to be Deaf in a hearing world and recognize a self-identity as hearing.

Although aspirational capital was not specifically supported by the results of this research, mentors may consider encourag- ing mentees to reach out to deaf scientists as potential role models. As within-group role models, deaf scientists can offer knowledge of strategies about how to navigate graduate school, conferences, and other aspects of academic science (Lee, 2006; Williamson, 2007; Listman et al., 2011).

Finally, this survey may yield useful information about mentoring relationships with deaf mentees. For downstream application of this survey, we recommend that the test administrator average the item scores belonging to each factor. Calculating factor scores using the more complicated regression method based on factor loadings would not add meaningful information (DiStefano et al., 2009).

\section{Study Limitations}

We recognize that our study has limitations. First, it is limited by the retrospective nature of the data collection, in that our participant pool contained deaf students who have persisted in STEM and already have some measure of success. We were unable to capture deaf students who left STEM fields, perhaps due to a poor research mentoring experience. Second, $27.2 \%$ of those invited to participate did not return the survey. The reasons behind their decision not to participate are unknown. It is possible that their reluctance to participate may be because they had a negative mentored-research experience. Therefore, it is possible that our survey results are weighted toward individuals with positive mentoring experiences. However, this bias would affect average factor scores and not the factor analysis per se, which analyzed the segregation of items into factors, so we are confident about the identification of the factors. We suggest that, for downstream application, recruitment bias issues could be resolved by administering the DMS before the end of mentored research experiences.

An important limitation in interpreting our results is that the four factor scores from the DMS have not yet been externally validated by correlating them with practical outcomes such as persistence in science. The DMS only measures the mentee's perception of acquisition of capital from a mentoring relationship. Although our qualitative interview data reinforce that mentees thought that each item in these four factors was important for their success, we do not know their relative importance or their correlations with persistence and other practical endpoints. We are planning a future study to look at survey subscores and establish such correlations over the longer term.

Finally, the statistical approach that we used to analyze our data set (principal-axis factor analysis) precludes making theoretically defensible inferences about the population of deaf mentees. One challenge of doing research with the Deaf community is the small potential pool of participants, and mentors and mentees working in STEM fields often know one another. We were unable to obtain a sufficiently random data set that would have allowed us to perform maximum-likelihood factor analysis and make these inferences.

\section{ACKNOWLEDGMENTS}

We thank Regina Nuzzo for statistical consulting. We thank our survey participants, expert faculty focus group participants, and interviewees, whose willingness to contribute to this work made this research possible. 


\section{REFERENCES}

Aikens ML, Sadselia S, Watkins K, Evans M, Eby LT, Dolan EL (2016). A social capital perspective on the mentoring of undergraduate life science researchers: an empirical study of undergraduate-postgraduate-faculty triads. CBE Life Sci Educ 15, ar16.

Anscombe N (2007, March 30). Deaf to the needs of hearing-impaired scientists Science Career Magazine, doi: 10.1126/science.caredit.a0700044.

Astin AW (1977). Four Critical Years: Effects of College on Beliefs, Attitudes, and Knowledge, San Francisco: Jossey-Bass.

Barlow AEL, Villarejo M (2004). Making a difference for minorities: evaluation of an educational enrichment program. J Res Sci Teach 41, 861-881.

Berk RA, Berg J, Mortimer R, Walton-Moss B, Yeo TP (2005). Measuring the effectiveness of faculty mentoring relationships. Acad Med 80, 66-71.

Bourdieu P (1986). The forms of capital. In: Education Culture, Economy and Society, ed. AH Halsey, H Lauder, P Brown, and AS Wells, Oxford University Press, 46-58.

Clark MD, Daggett DJ (2015). Exploring the presence of a Deaf American cultural life script. Deafness Educ Int 17, 194-203.

Dawson P (2014). Beyond a definition: toward a framework for designing and specifying mentoring models. Educ Res 43, 137-145.

DiStefano C, Zhu M, Mîndrilă D (2009). Understanding and using factor scores: considerations for the applied researcher. Pract Assess Res Eval 14(20), 1-11.

Eby LT, Dolan EL (2015). Mentoring in postsecondary education and organizational settings. In: APA Handbook of Career Intervention, Vol 2: Applications, ed. PJ Hartung, ML Savickas, and WB Walsh, Washington, DC American Psychological Association, 383-395.

Field A (2013). Discovering Statistics Using IBM SPSS Statistics, 4th ed., Los Angeles: Sage.

Fleming M, House S, Hanson VS, Yu L, Garbutt J, McGee R, Kroenke K, Abedin Z, Rubio DM (2013). The Mentoring Competency Assessment. Acad Med 88, 1002-1008.

Gasiewski JA, Eagan MK, Garcia GA, Hurtado S, Chang MJ (2012). From gatekeeping to engagement: a multicontextual, mixed method study of student academic engagement in introductory STEM courses. Res High Educ 53, 229-261.

Glickman ME, Rao SR, Schultz MR (2014). False discovery rate control is a recommended alternative to Bonferroni-type adjustments in health studies. J Clin Epidemiol 67, 850-857.

Goodhue DL, Loiacono ET (2002). Randomizing survey question order vs. grouping questions by construct: an empirical test of the impact on apparent reliabilities and links to related constructs. In: Proceedings of the 35th Annual Hawaii International Conference on System Sciences, held 10 January 2002. IEEE, 3456-3465

Haeger H, Fresquez C (2016). Mentoring for inclusion: the impact of mentoring on undergraduate researchers in the sciences. CBE Life Sci Educ $15, \operatorname{ar} 36$.

Hanauer DI, Dolan EL (2014). The Project Ownership Survey: measuring differences in scientific inquiry experiences. CBE Life Sci Educ 13, 149-158.

Hathaway R, Nagda BA, Gregerman SR (2002). The relationship of undergraduate research participation to graduate and professional educational pursuit: an empirical study. J College Stud Devel 43, 614-631.

Hauser PC (2013). Deaf scientists need deaf mentors. In: Proceedings of the 6th International Deaf Academics and Researchers Conference, held July in Lisbon, Portugal.

Hulsebosch P, Myers LR (2002). Minority parents as cultural mediators for education: deaf parents mentoring hearing parents of deaf children School Community J 12, 73-89.

Irvine JJ (1991). Black Students and School Failure. Policies, Practices, and Prescriptions, Westport, CT: Praeger.

Jacobi M (1991). Mentoring and undergraduate academic success: a literature review. Rev Educ Res 61, 505-532.

Junge B, Quiñones C, Kakietek J, Teodorescu D, Marsteller P (2010). Promoting undergraduate interest, preparedness, and professional pursuit in the sciences: an outcomes evaluation of the SURE program at Emory University. CBE Life Sci Educ 9, 119-132.

Kellam SG, Wang W, Mackenzie ACL, Brown CH, Ompad DC, Or F, lalongo NS, Poduska JM, Windham A (2012). The impact of the good behavio game, a universal classroom-based preventive intervention in first and second grades, on high-risk sexual behaviors and drug abuse and dependence disorders into young adulthood. Prev Sci 15(S1) $6-18$.

Killpack TL, Melón LC (2016). Toward inclusive STEM classrooms: what personal role do faculty play? CBE Life Sci Educ 15, es3.

Ladson-Billings $G$ (1998). Just what is critical race theory, and what's it doing in a nice field like education? Qualitative Studies Educ 11, 7-24.

Lee MB (2006). Ethnicity Matters: Rethinking How Black, Hispanic, \& Indian Students Prepare for and Succeed in College, New York: Lang.

Listman J, Rogers KD, Hauser PC (2011). Community cultural wealth and deaf adolescents' resilience. In: Resilience in Deaf Children: Adaptation through Emerging Adulthood, ed. DH Zand and KJ Pierce, Berlin: Springer Science, 279-297.

Listman JD (2013). Nature of deaf mentoring dyads: role of subjugated knowledge. PhD Dissertation, Rochester, NY: St. John Fisher College.

Lopatto D (2004). Survey of Undergraduate Research Experiences (SURE): first findings. Cell Biol Educ 3, 270-277.

Lopatto D (2007). Undergraduate research experiences support science career decisions and active learning. CBE Life Sci Educ 6, 297-306.

MacCallum RC, Widaman KF, Zhang S, Hong S (1999). Sample size in factor analysis. Psychol Methods 4, 84-99.

McGee R, Keller JL (2007). Identifying future scientists: predicting persistence into research training. CBE Life Sci Educ 6, 316-331.

McKee MM, Smith S, Barnett S, Pearson TA (2013). Commentary: what are the benefits of training deaf and hard-of-hearing doctors? Acad Med 88 158-161.

Nagda BA, Gregerman SR, Jonides J, Hippel von W, Lerner JS (1998). Undergraduate student-faculty research partnerships affect student retention. Rev High Educ 22, 55-72.

National Science Foundation (NSF) (2007). Women, Minorities, and Persons with Disabilities in Science and Engineering, Report No. 07-315, Arlington, VA: National Center for Science and Engineering Statistics.

NSF (2009). Women, Minorities, and Persons with Disabilities in Science and Engineering, Report No. 09-305, Arlington, VA: National Center for Science and Engineering Statistics.

NSF (2011). Women, Minorities, and Persons with Disabilities in Science and Engineering, Report No. 11-309, Arlington, VA: National Center for Science and Engineering Statistics.

Nuzzo RL (2016). The box plots alternative for visualizing quantitative data PM R 8, 268-272.

President's Council of Advisors on Science and Technology (2012). Engage to Excel: Producing One Million Additional College Graduates with Degrees in Science, Technology, Engineering and Mathematics, Washington, DC: U.S. Government Office of Science and Technology, $1-130$.

Saur R, Rasmussen S (2003). Butterfly power in the art of mentoring deaf and hard of hearing college students. Mentoring and Tutoring 11, 195209

Schlosser LZ, Gelso CJ (2001). Measuring the working alliance in advisor-advisee relationships in graduate school. J Counsel Psych 48, $157-$ 167.

Schlosser LZ, Gelso CJ (2005). The Advisory Working Alliance InventoryAdvisor Version: scale development and validation. J Counsel Psych 52 650-654.

Schmitt N, Stults DM (1985). Factors defined by negatively keyed items: the result of careless respondents? Appl Psych Meas 9, 367-373.

Seymour E, Hewitt N (1997). Talking about Leaving: Why Undergraduates Leave the Sciences, Boulder, CO: Westview.

Solomon CM, Braun DC, Kushalnagar R, Ladner RF, Lundberg D, Painter R Nuzzo R (2013). Workshop for Emerging Deaf and Hard of Hearing Scientists: A White Paper, Washington, DC: Gallaudet University. http://doit-prod.s.uw.edu/accesscomputing/sites/default/files/ manual-upload/WhitePaper-Final_Gallaudet_Emerging_Sci_2_15_13 pdf (accessed 22 July 2015).

Sturgis P, Roberts C, Smith P (2014). Middle alternatives revisited: how the neither/nor response acts as a way of saying "I Don't Know"? Sociol Methods Res 43, 15-38. 
Thiry H, Weston TJ, Laursen SL, Hunter A-B (2012). The benefits of multi-year research experiences: differences in novice and experienced students' reported gains from undergraduate research. CBE Life Sci Educ 11, 260-272.

Thompson JJ, Conaway E, Dolan EL (2015). Undergraduate students' development of social, cultural, and human capital in a networked research experience. Cult Stud Sci Educ 11, 959-990.

Treisman PU (1992). Studying students studying calculus: a look at the lives of minority mathematics students in college. Coll Math J 23, 362.

Treisman PU (2013). Leveraging knowledge from developmental sciences for improving modern STEM education. Proceedings of the Society for Research in Child Development, held 18 April 2013 in Seattle, WA.

Villarejo M, Barlow AEL, Kogan D, Veazey BD, Sweeney JK (2008). Encouraging minority undergraduates to choose science careers: career paths survey results. CBE Life Sci Educ 7, 394-409.
Williamson CE (2007). Black Deaf Students: A Model for Educational Success, Washington, DC: Gallaudet University Press.

Willis GB (2004). Cognitive Interviewing: A Tool for Improving Questionnaire Design, Thousand Oaks, CA: Sage.

Wilson ZS, Holmes L, deGravelles K, Sylvain MR, Batiste L, Johnson M, McGuire SY, Pang SS, Warner IM (2011). Hierarchical mentoring: a transformative strategy for improving diversity and retention in undergraduate STEM disciplines. J Sci Educ Technol 21, 148-156.

Woodcock K, Rohan MJ, Campbell L (2007). Equitable representation of deaf people in mainstream academia: why not? High Educ 53, 359-379.

Worthington RL, Whittaker TA (2006). Scale development research: a content analysis and recommendations for best practices. Couns Psychol 34, 806-838.

Yosso TJ (2005). Whose culture has capital? A critical race theory discussion of community cultural wealth. Race Ethnicity Educ 8, 69-91. 